\title{
Integrating cluster analysis with MCDM methods for the evaluation of local agricultural production
}

\author{
Nuri Omurbek $^{1}$, Onur Akcakaya ${ }^{2, *}$ and Ezgi Dilan Urmak Akcakaya ${ }^{2}$ \\ ${ }^{1}$ Faculty of Economics and Administrative Sciences, Suleyman Demirel University, Isparta, Turkey \\ E-mail: 〈nuriomurbek@sdu.edu.tr〉 \\ ${ }^{2}$ Faculty of Economics and Administrative Sciences, University of Ardahan, Ardahan, Turkey \\ E-mail: 〈\{onurakcakaya, ezgidilanurmak\}@ardahan.edu.tr〉
}

\begin{abstract}
This study aims to cluster Turkish cities based on their local agricultural production and rank them in terms of performance by combining cluster analysis and multi-criteria decision-making (MCDM) methods. In this context, a three-phase methodology is developed. In the first phase, Ward's method is utilized to cluster cities according to agricultural production characteristics. In the second phase, the objective criteria weights are determined using the Criteria Importance Through Intercriteria Correlation technique (CRITIC). In the third phase, to rank the clusters in terms of performance, the Technique for Order Preference by Similarity to Ideal Solution (TOPSIS) method is applied. Due to the results, the 81 cities are divided into six clusters in terms of agricultural production features. The cluster with the highest performance is Cluster 6, in which Konya is alone. Cluster 4, which includes Antalya and Mersin, follows this cluster. Cluster 1 with 25 cities and Cluster 2 with 19 cities are the clusters with the lowest results. The results show that only a few cities such as Konya, Antalya, and Mersin are generating more than tens of them in combination. These findings reveal that local governments should reconsider their agricultural programs and develop new strategies under the direction of the central government.
\end{abstract}

Keywords: Cluster analysis, local governments, multi-criteria decision-making, performance measurement, urban agriculture

Received: March 21, 2021; accepted: September 6, 2021; available online: December 23, 2021

DOI: $10.17535 /$ crorr.2021.0009

\section{Introduction}

Agriculture has long been regarded as a rural activity. However, this has started to change since the discovery of its potential. Agriculture provides significant advantages to the urban economy such as bringing money to farmers and providing food for citizens. It also makes a critical contribution to urban food security [35].

The identification of the basic drivers of agricultural production is absolutely required to create effective public policy [29]. Measuring performance is also important in this regard. The primary goal of performance evaluation is to achieve effective and efficient project performance by providing an information flow to project management at each stage [28]. This helps decisionmakers to decide how to increase effectiveness and efficiency with the available resources [14].

In this context, this paper aims to cluster Turkish Cities according to their local agricultural production and to rank them in terms of performance by using cluster analysis and multi-criteria decision-making (MCDM) methods in an integrated way. This aim includes two main objectives.

*Corresponding author. 
The initial step is to look for cities with similar production characteristics. As a result, units in the same cluster will be able to cooperate more effectively in the future in terms of decisionmaking and implementation. The second objective is to determine the best performance among all clusters. Thus, it is expected that the performance distribution of agricultural production throughout the country can be defined by local units. This may provide the local units with the advantage of determining their current positions, as well as strengthen the competition among themselves.

To achieve these two goals, first, we construct the nine agricultural production criteria, based on the literature, expert opinions, and data availability. The data set for each criterion is collected from the database of the Turkish Statistical Institute (TUIK). It includes values belonging to nine agricultural production criteria between 2007-2018. At the clustering phase, we converted the annual data into average because using only one year's data would not be logical for the evaluation.

The availability of data is an additional factor in determining the criteria because it is not easy to find quality and regular data for certain criteria. For instance, the criterion of the amount of vegetables and fruits produced in the greenhouse is not accessible for all cities. Hence, we had to eliminate some criteria. Also, no data exists for some agricultural activities such as the fishing industry.

In this context, we develop a three-step approach that combines Ward's, the Criteria Importance Through Intercriteria Correlation Technique (CRITIC), and the Technique for Order Preference by Similarity to Ideal Solution (TOPSIS) methods. In the first phase, Ward's method is used to find the most similar couple of clusters. In the second phase, CRITIC is utilized for determining the objective weights of agricultural production indicators, and in the third phase, TOPSIS is used to evaluate in terms of their performance.

The remainder of this paper is organized as follows: Section 2 includes a review of the literature on related studies. Section 3 presents the information about the data used in the paper. Section 4 lays out a detailed description of the methodology. The empirical application is given in Section 5 by utilizing the application steps. In this section, results are also presented. Finally, Section 6 discusses the findings, provides concluding remarks, and makes suggestions for future studies.

\section{Literature Review}

Similar to this study, some decision-making problems require additionally classifying alternatives based on similar characteristics, so additional methods may be required. Cluster analysis is a useful method for such situations because it can predetermine the clusters that consist of similar objects [11]. Cluster analysis has been used in studies from across various research fields, such as in reviewing applications of cluster analysis in marketing and presenting alternative methods of cluster analysis [34]; exploring host communities' perceptions of tourism [33]; comparing spectral, hierarchical and k-clustering in e-nose data-sets [16]; determining the efficiency of at regulation on greenhouse gas emissions [2]; determining the impact of dimensionality reduction on stock in distinct market situations [13]; and the analysis of water quality [10]. One of the widespread hierarchical clustering techniques is Ward's method [39]. Ward's method has been applied in many studies, such as in comparing various clustering methods for the clustering of mixed-mode data [9], analyzing healthcare systems [24], comparing two clustering methods in portfolio management [20], developing software for data analysis [26], and researching combinations of distance metrics and hierarchical clustering criteria [42].

MCDM methods are applicable to solving decision-making problems [23]. Recently, they have become increasingly popular in decision-making with multi-dimensional attributes [38]. TOPSIS is one of the MCDM methods and it is widely used, either separately or integrated with other methods, to solve at multitude of decision-making problems. It has been utilized in a 
large number of studies, such as with compromise solutions [30], researching the applications of TOPSIS [5], measuring the efficiency of economic sectors [4], selecting suppliers [22], selecting a location for a liquefied natural [3], assessing sustainable housing affordability [25], evaluating the ecological-economic efficiency of innovations in green technology [37], selecting an optimal road safety composite index [36], assessing integrated flood vulnerability [41], and selecting biological nano-materials [43].

In multi-criteria decision-making models, determining criteria weight coefficients is a critical step. The CRITIC approach is one of the most extensively utilized and well-known objective methods. It is a correlation approach that determines criteria contrasts by using the standard deviation of ranking criteria values of alternatives per column, as well as the correlation coefficients of all paired columns [44]. The CRITIC Method has been used in a large number of decision-making studies to determine objective weights [27, 31, 40].

\section{The Data}

In this section, we purpose to provide a series of data to cluster and evaluate the cities in Turkey in terms of agricultural production criteria. Based on the literature, expert opinions, and data availability, we constructed the nine criteria, as follows: (C1) The number of cattle (pcs), (C2) the value of live animals (thousand Turkish Lira [TL]), (C3) the value of animal production (thousand TL), (C4) the agricultural production value (TL per capita), (C5) the number of small cattle (pcs), (C6) the production amount of cereals and other plant products (ton), (C7) the total cultivated agricultural area (hectare), (C8) the total value of agricultural production (thousand TL), (C9) and the total value of plant production (thousand TL). For convenience, we gave codes to the criteria in the methodology. The data set for each criterion is collected from the database of TUIK.

\section{Methodology}

This section aims to lay out the methodology of the paper. We develop a three-step approach integrating cluster analysis and MCDM methods. The methodology applied in this study is given in Figure 1.

Phase I: Clustering

The data was collected from the database of TUIK and the average data was calculated between 2007-2018. Utilizing Ward's method, all cities were clustered according to their agricultural production features.

Phase II: Weighting
CRITIC method is used for determining the objective weights of agricultural production indicators.

Phase III: Ranking

Clusters were evaluated in terms of agricultural production performance, by applying the TOPSIS method.

Figure 1: Three-Step Approach

\subsection{Ward's Method}

Ward's method is a common hierarchical clustering method that composes clusters so that the variance within the clusters is minimal. It determines a cluster as a gathering of objects such that the error sum of squares amongst the members of each cluster is minimal [6].

The treatment of Ward's method can be summarized briefly as follows. Firstly, it is assumed that there are $N$ elements to a cluster. It starts with $N$ clusters consisting of one entity. Then, 
the similarity matrix is searched for the most similar pairs, and by combining them the number of clusters is reduced to one. These steps are applied until all clusters are obtained [15].

\subsection{CRITIC Method}

The steps of the CRITIC method are as follows [8]:

Step 1: Structure of the decision matrix

Consider a decision matrix, $X=\left[x_{i j}\right]_{m \times n}$, where $x_{i j}$ is the performance measurement of the $i$-th alternative in respect to the $j$-the criterion.

$\mathrm{m}:$ is the number of alternatives

$\mathrm{n}$ : is the number of criteria

Step 2: Normalization of the decision matrix

Normalizing the decision matrix by using (1) and (2):

$$
\begin{aligned}
r_{i j}= & \frac{x_{i j}-x_{j}^{\min }}{x_{j}^{\max }-x_{j}^{\min }} \text { benefit-based } \\
r_{i j} & =\frac{x_{j}^{\max }-x_{i j}}{x_{j}^{\max }-x_{j}^{\min }} \text { cost-based } \\
x_{j}^{\max } & =\max \left(x_{i j}, \quad 1, \ldots, 6\right) \\
x_{j}^{\min } & =\max \left(x_{i j}, \quad 1, \ldots, 6\right)
\end{aligned}
$$

Step 3: Calculate the criteria weights

In the determination of criteria weights, both the standard deviation of the criterion and its correlation between other criteria are included. The weight of the $i$-th criterion $w_{j}$ is calculated by (3):

$$
w_{j}=\frac{C_{j}}{\sum_{k=1}^{n} C_{i}}
$$

Where $C_{j}$ is the quantity of information contained in the $j$-th criterion obtained by (4):

$$
C_{j}=\sigma_{j} \sum_{k=1}^{n}\left(1-r_{j k}\right)
$$

$\sigma_{j}$ : the standard deviation of the $j$-th criterion

$r_{j k}$ : the linear correlation coefficient between the $j$-th and the $i$-th criteria.

\subsection{TOPSIS Method}

The TOPSIS method is utilized to overcome multiple decision-making problems [7]. The ideal solution minimizes the cost criteria and maximizes the benefit criteria, while the negative-ideal solution maximizes the cost criteria and minimizes the benefit criteria [32]. The steps of the TOPSIS method are as follows [21]: 
Step 1: Structure of the decision matrix

Evaluating the decision matrix which includes $m$ alternatives in association with $n$ criteria.

\section{Step 2: Normalization of the decision matrix}

It is required to normalize the original matrix to ensure that all the criteria are equivalent and in the same form. The normalized decision matrix is $R=\left[r_{i j}\right]_{m x n}$, which is obtained by $(5)$.

$$
r_{i j}=\frac{x_{i j}}{\sqrt{\sum_{j=1}^{m} x_{i j}^{2}}} i=1, \ldots, 6 ; j=1, \ldots, 9
$$

Step 3: Obtain the weighted normalized decision matrix

The weighted decision matrix is calculated by the normalized decision matrix multiplied with the weights of the indexes as illustrated by (6).

$$
v_{i j}=w_{i} r_{i j} \quad i=1, \ldots, 6 ; j=1, \ldots, 9
$$

Step 4: Determine the ideal and negative - ideal solutions

The ideal solution is composed of the optimal value of each criterion from the weighted decision matrix as illustrated by (7). The negative ideal solution is composed of the worst value of each criterion from the weighted decision matrix as illustrated by (8).

$$
\begin{gathered}
A^{*}=\left\{\left(\max _{i} v_{i j} \mid j \in J\right),\left(\min _{i} v_{i j} \mid j \in J^{\prime}\right)\right\} \\
A^{*}=\left\{v_{1}^{*}, v_{2}^{*}, v_{3}^{*}, \ldots, v_{n}^{*}\right\} \\
A^{-}=\left\{\left(\min _{i} v_{i j} \mid j \in J\right),\left(\max _{i} v_{i j} \mid j \in J^{\prime}\right)\right\} \\
A^{-}=\left\{v_{1}^{-}, v_{2}^{-}, v_{3}^{-}, \ldots, v_{n}^{-}\right\}
\end{gathered}
$$

Step 5: Calculate the separation measure

The distance of every feasible solution from the ideal solution and the negative ideal solution is calculated in turn as illustrated by (9) and (10).

$$
\begin{gathered}
S_{i}^{*}=\sqrt{\sum_{j=1}^{n}\left(v_{i j}-v_{j}^{*}\right)^{2}} \\
S_{i}^{-}=\sqrt{\sum_{j=1}^{n}\left(v_{i j}-v_{j}^{-}\right)^{2}}
\end{gathered}
$$

Step 6: Determine the relative closeness to the ideal solution 
The relative degree of approximation is calculated by (11).

$$
C_{i}=\frac{S_{i}^{-}}{S_{i}^{-}+S_{i}^{+}} \quad\left(0 \leq C_{i} \leq 1 ; \quad i=1,2, \ldots, 6\right)
$$

The alternative is sorted in accordance with the value of the relative degree of approximation. The bigger the value is, the better the alternative is.

\section{Empirical Application}

The purpose of this section is to give information about the implementation of the methodology and the results. The implementation has two phases in parallel with the scope.

\subsection{Clustering Cities According to Agricultural Production Criteria}

Firstly, we calculated the arithmetic mean of the data to obtain the average data set. Thus, we obtained a decision matrix containing all cities. Then, the summary statistics table of the decision matrix was obtained (Table1).

\begin{tabular}{|c|c|c|c|c|r|r|}
\hline & N & Minimum & Maximum & Mean & $\begin{array}{c}\text { Std. } \\
\text { Deviation }\end{array}$ & \multicolumn{1}{|c|}{ Variance } \\
\hline C1 & 81 & 9527,666666666 & 629998,8333333 & 166042,9711934 & 130004,1059788 & 16901067571 \\
\hline C2 & 81 & 47495,91666666 & 3433847,500000 & 818874,8518518 & 607144,8323366 & 368624847433 \\
\hline C3 & 81 & 28005,33333333 & 1352852,583333 & 327116,7109053 & 257602,5820814 & 66359090295 \\
\hline C4 & 81 & 70,83333333333 & 10995,75000000 & 3766,567901234 & 1914,374171432 & 3664828 \\
\hline C5 & 81 & 5367,750000000 & 2550449,333333 & 452003,6738683 & 442389,236290 & 195708236385 \\
\hline C6 & 81 & 895,6666666666 & 10849041,00000 & 1189113,442386 & 1385309,697526 & 1919082958059 \\
\hline C7 & 81 & 797,0000000000 & 1939459,416666 & 256596,8014403 & 285744,2979616 & 81649803817 \\
\hline C8 & 81 & 259319,5833333 & 9722506,166666 & 2352525,224279 & 1890689,634293 & 357470729322 \\
\hline C9 & 81 & 31873,58333333 & 7367297,166666 & 1206533,662551 & 1297030,148297 & 168228720559 \\
\hline $\begin{array}{c}\text { Valid N } \\
\text { (listwise) }\end{array}$ & 81 & & & & & \\
\hline
\end{tabular}

Table1: Descriptive Statistics

Cluster analysis has the advantage of not making any assumptions about the number of clusters or cluster structure [17]. In addition, it is another advantage that assumptions such as normality, linearity, and homoscedasticity, which are important in other multivariate statistical analysis techniques, are not taken into account in cluster analysis [12].

Ward's method was chosen due to its several advantages over other algorithms. These are as follows: (1) There is no need to predetermine the number of clusters. The methods decides how many clusters there should be. (2) The procedure can be applied to any number of clusters between 1 to $\mathrm{N}$, where $\mathrm{N}$ is the total number of elements in the original set. (3) It is one of the few techniques that actually reduces the total square error. (4) Ward's method allows cluster analysis to be performed even with a limited number of observations [18]. By utilizing Ward's method, a dendrogram was created to determine the clusters. With the help of a dendrogram, clusters were listed from top to bottom. The dendrogram is scaled from left to right as $0-25$ units. This scale serves to show the distance between the clusters. In terms of the data used in the dendrogram, the cities that are most similar to each other form a cluster at a distance of one unit, while the cities that are least similar to each other come together at a distance of 25 units. (Figure 2). According to these results, six clusters were produced at a distance of one unit and all cities were divided into six clusters (Table 2). 


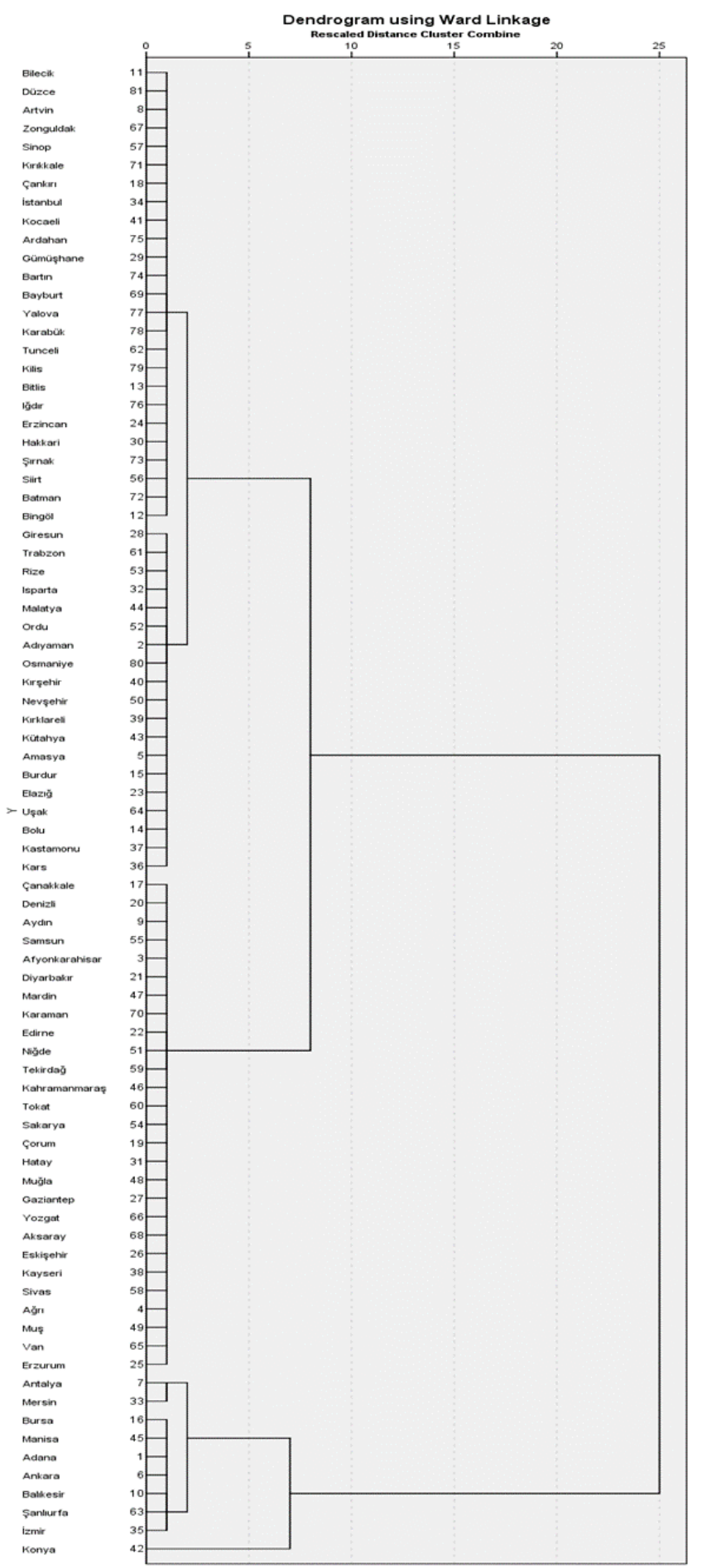

Figure 2: Structural model: standardized solution. 


\begin{tabular}{|l|l|l|l|l|l|l|}
\hline & Cluster 1 & Cluster 2 & Cluster 3 & Cluster 4 & Cluster 5 & Cluster 6 \\
\hline 1 & Bilecik & Giresun & Canakkale & Antalya & Bursa & Konya \\
\hline 2 & Düzce & Trabzon & Denizli & Mersin & Manisa & \\
\hline 3 & Artvin & Rize & Aydin & & Adana & \\
\hline 4 & Zonguldak & Isparta & Samsun & & Ankara & \\
\hline 5 & Sinop & Malatya & Afyonkarahisar & & Balikesir & \\
\hline 6 & Kirikkale & Ordu & Diyarbakir & & Sanliurfa & \\
\hline 7 & Cankiri & Adiyaman & Mardin & & Izmir & \\
\hline 8 & Istanbul & Osmaniye & Karaman & & & \\
\hline 9 & Kocaeli & Kirsehir & Edirne & & & \\
\hline 10 & Ardahan & Nevsehir & Nigde & & & \\
\hline 11 & Gumushane & Kirklareli & Tekirdag & & & \\
\hline 12 & Bartin & Kutahya & Kahramanmaras & & & \\
\hline 13 & Bayburt & Amasya & Tokat & & & \\
\hline 14 & Yalova & Burdur & Sakarya & & & \\
\hline 15 & Karabuk & Elazig & Corum & & & \\
\hline 16 & Tunceli & Usak & Hatay & & & \\
\hline 17 & Kilis & Bolu & Mugla & & & \\
\hline 18 & Bitlis & Kastamonu & Gaziantep & & & \\
\hline 19 & Igdir & Kars & Yozgat & & & \\
\hline 20 & Erzincan & & Aksaray & & & \\
\hline 21 & Hakkari & & Eskisehir & & & \\
\hline 22 & Sirnak & & Kayseri & & & \\
\hline 23 & Siirt & & Sivas & & & \\
\hline 24 & Batman & & Mgri & & & \\
\hline 25 & Bingol & & Ean & & & \\
\hline 26 & & & & & & \\
\hline 27 & & & & & \\
\hline
\end{tabular}

Table 2: Clusters produced with Ward's method

\begin{tabular}{|c|r|r|r|r|r|r|r|r|r|}
\hline & C1 & C2 & \multicolumn{1}{c|}{ C3 } & C4 & \multicolumn{1}{c|}{ C5 } & C6 & C7 & C8 & C9 \\
\hline Cluster 1 & 18,04 & 17,96 & 17,20 & 34,48 & 28,44 & 17,96 & 18,40 & 13,00 & 16,00 \\
\hline Cluster 2 & 38,95 & 34,42 & 37,95 & 48,89 & 29,21 & 30,63 & 35,37 & 35,68 & 39,26 \\
\hline Cluster 3 & 55,70 & 56,11 & 55,04 & 44,15 & 50,56 & 60,22 & 57,78 & 57,52 & 52,37 \\
\hline Cluster 4 & 39,00 & 59,50 & 52,00 & 46,50 & 73,50 & 40,50 & 53,50 & 79,00 & 80,50 \\
\hline Cluster 5 & 66,71 & 71,86 & 71,29 & 26,71 & 66,14 & 71,71 & 63,00 & 75,14 & 74,43 \\
\hline Cluster 6 & 81,00 & 81,00 & 81,00 & 58,00 & 80,00 & 81,00 & 81,00 & 81,00 & 79,00 \\
\hline$\chi^{2}$ & 45,769 & 52,770 & 50,444 & 7,755 & 30,910 & 60,513 & 47,466 & 72,543 & 57,019 \\
\hline df & 5 & 5 & 5 & 5 & 5 & 5 & 5 & 5 & 5 \\
\hline $\begin{array}{c}\text { Asymp. } \\
\text { Sig. }\end{array}$ & 0,000 & 0,000 & 0,000 & 0,170 & 0,000 & 0,000 & 0,000 & 0,000 & 0,000 \\
\hline
\end{tabular}

Table 3: The Kruskal Wallis Test Results

The fact that the clusters contain a different number of cities is due to their variance in agricultural production criteria such as the number of cattle, the value of live animals, the value of animal production, agricultural production value, the number of small cattle, the production amount of cereals and other plant products, the total cultivated agricultural area, the total value of agricultural production, and the total value of plant production. In addition to criteria related to the amount and value of animal/plant production, criteria related to suitable lands 
for agriculture is also effective in clustering. The city of Konya was included in Cluster 6 alone because this city is unique among all other cities in terms of agricultural production potential and production criteria. It is also in the leading position.

The Kruskal Wallis test was applied to determine whether there is a significant difference between the clusters in terms of each criterion (Table 3).

According to the Kruskal Wallis test results, it was observed that there were statistically significant differences between the clusters in terms of other criteria, except for the agricultural production value per capita $(\mathrm{C} 4)$ criterion.

\subsection{Ranking Clusters According to Agricultural Production Criteria}

The purpose of this section is to rank clusters produced in the first phase from best to the worst in terms of agricultural production values. While the TOPSIS method was applied in the evaluation of the clusters, the CRITIC method was used in determining the objective criteria weights required for the application of the TOPSIS method.

The CRITIC method was chosen due to its several advantages over other methods. (1) It allows a more objective evaluation by considering the correlation coefficients between the variables. Thus, the weights of the criteria are determined objectively by avoiding the negative effects that may be caused by the subjective interpretations of the decision maker. (2) CRITIC is a simpler technique that requires less computational effort [8]. (3) It does not distinguish between beneficial and non-beneficial criteria, instead attempting to assess the severity of the contrast in the decision making problem's structure [1].

TOPSIS was chosen due to its several advantages over other MCDM methods. The TOPSIS Method has: (1) a sound logic that embodies the rationale of human choice, (2) a scalar value that considers both the best and worst options simultaneously, and (3) a simple computation procedure that can be easily programmed in a spreadsheet [19].

Firstly, by utilizing the decision matrix, the average values of the criteria were calculated for each cluster. Thus, a new decision matrix was obtained for both the CRITIC and TOPSIS methods (Table 4).

By utilizing the CRITIC method, the weights of criteria were obtained (Table 5). According to the criterion weights, the criterion of agricultural production value per capita (C4) was determined to be the most important criterion with a value of 0.264 and, the number of small cattle (C5) is the least important criterion with a value of 0.066 (Table 5).

To obtain a ranking of clusters, the TOPSIS method was used. Firstly, Equation (5) was utilized to normalize the decision matrix. Then, the weighted decision matrix was created by multiplying the normalized values with the weights for each criterion. Criterion weights obtained by the CRITIC method were used to obtain the weighted decision matrix. The ideal $\left(A^{*}\right)$ and negative-ideal $\left(A^{-}\right)$solution values for each criterion were calculated by using Equation $(7)$ and Equation (8), respectively. The positive ideal solution is the one that maximizes the benefit criterion while minimizing the cost criterion. The negative ideal solution, on the other hand, is considered to be the solution that maximizes the cost criterion while minimizing the benefit criterion. By utilizing the ideal and negative-ideal solution values, the distance values to the ideal and negative-ideal points $\left(S_{i}^{*}\right.$ and $\left.S_{i}^{-}\right)$were calculated using Equation (9) and Equation (10), respectively. In the last step, the relative closeness to the ideal solution $\left(C_{i}^{*}\right)$ was calculated by utilizing Equation (11) (Table 6). Clusters were listed from greatest to smallest according to their closeness to the ideal solution $C_{i}^{*}$ (Table 7). 


\begin{tabular}{|l|c|r|r|r|r|r|r|r|r|}
\hline & C1 & \multicolumn{1}{|c|}{ C2 } & \multicolumn{1}{c|}{ C3 } & \multicolumn{1}{c|}{ C4 } & \multicolumn{1}{c|}{ C5 } & \multicolumn{1}{c|}{ C6 } & \multicolumn{1}{c|}{ C7 } & C8 & C9 \\
\hline Cluster 1 & 70985.87 & 354283.61 & 136740.94 & 3309.72 & 258573.68 & 307040.5 & 77562.81 & 756140.78 & 265116.23 \\
\hline Cluster 2 & 140599.19 & 618794.89 & 270942.87 & 4318.61 & 230303.57 & 645016.43 & 170529.72 & 1682333.51 & 792595.74 \\
\hline Cluster 3 & 221394.96 & 1044244.50 & 397489.85 & 4039.04 & 589061.77 & 1713894.76 & 348740.95 & 2796429.38 & 1354695.02 \\
\hline Cluster 4 & 127326.91 & 960644.54 & 354364.75 & 3865.20 & 947413.16 & 823283.58 & 279436.5 & 7520818.79 & 6205809.5 \\
\hline Cluster 5 & 305876.04 & 1737847.33 & 733743.90 & 2699.48 & 878172.35 & 2516585.32 & 527266.79 & 5631278.52 & 3159687.28 \\
\hline Cluster 6 & 629998.83 & 3433847.5 & 1352852.58 & 4614.25 & 1825487 & 10849041 & 1939459.41 & 9722506.16 & 4935806.08 \\
\hline
\end{tabular}

Table 4: Decision Matrix

\begin{tabular}{|c|c|c|c|c|c|c|c|c|c|}
\hline & C1 & C2 & C3 & C4 & C5 & C6 & C7 & C8 & C9 \\
\hline$w_{j}$ & 0.0783931 & 0.0684993 & 0.0738479 & 0.2645838 & 0.0667720 & 0.0781508 & 0.0706274 & 0.1036582 & 0.1954671 \\
\hline
\end{tabular}

Table 5: Weights of criteria

\begin{tabular}{|l|r|r|c|}
\hline & \multicolumn{1}{|c|}{$S_{i}^{*}$} & \multicolumn{1}{c|}{$S_{i}^{-}$} & $C_{i}^{*}$ \\
\hline Cluster 1 & 0.209351509 & 0.017091773 & 0.075479268 \\
\hline Cluster 2 & 0.190247799 & 0.04860089 & 0.203479826 \\
\hline Cluster 3 & 0.16776605 & 0.055002542 & 0.246904383 \\
\hline Cluster 4 & 0.125117694 & 0.148963492 & 0.543501341 \\
\hline Cluster 5 & 0.13236103 & 0.090464524 & 0.405988103 \\
\hline Cluster 6 & 0.028590206 & 0.196491541 & 0.872978568 \\
\hline
\end{tabular}

Table 6: The values of $S_{i}^{*}, S_{i}^{-}$and $C_{i}^{+}$

\begin{tabular}{|l|c|l|}
\hline Clusters & \multicolumn{1}{|c|}{$C_{i}^{*}$} & \multicolumn{1}{c|}{ Cities } \\
\hline Cluster 6 & 0.872978568 & Konya \\
\hline Cluster 4 & 0.543501341 & Antalya, Mersin \\
\hline Cluster 5 & 0.405988103 & Bursa, Manisa, Adana, Ankara, Balikesir, Sanliurfa, Izmir \\
\hline Cluster 3 & 0.246904383 & $\begin{array}{l}\text { Canakkale, Denizli, Aydin, Samsun, Afyonkarahisar, } \\
\text { Diyarbakir, Mardin, Karaman, Edirne, Nigde, Tekirdag, } \\
\text { Kahramanmaras, Tokat, Sakarya, Corum, Hatay, Mugla, } \\
\text { Gaziantep, Yozgat, Aksaray, Eskisehir, Kayseri, Sivas, } \\
\text { Agri, Mus, Van, Erzurum }\end{array}$ \\
\hline Cluster 2 & 0.203479826 & $\begin{array}{l}\text { Giresun, Trabzon, Rize, Isparta, Malatya, Ordu, Adiyaman, } \\
\text { Osmaniye, Kirsehir, Nevsehir, Kirklareli, Kutahya, Amasya, } \\
\text { Burdur, Elazig, Usak, Bolu, Kastamonu, Kars }\end{array}$ \\
\hline Cluster 1 & 0.075479268 & $\begin{array}{l}\text { Bilecik, Duzce, Artvin, Zonguldak, Sinop, Kirikkale, } \\
\text { Cankiri, Istanbul, Kocaeli, Ardahan, Gumushane, Bartin, } \\
\text { Bayburt, Yalova, Karabuk, Tunceli, Kilis, Bitlis, Igdir, } \\
\text { Erzincan, Hakkari, Sirnak, Siirt, Batman, Bingol }\end{array}$ \\
\hline
\end{tabular}

Table 7: Cluster Ranking

\section{Conclusion}

In this paper, we purposed to cluster Turkish cities according to the criteria for agricultural production, and to evaluate the clusters according to their performance. For this purpose, we utilized a three-phase approach to address research questions. In the first phase, we utilized Ward's method for clustering all cities. In the second phase, the CRITIC was utilized for determining the objective weights of agricultural production indicators, and in the third phase, by using the TOPSIS method, we evaluated these clusters in terms of their agricultural efficiency.

This study makes two main contributions to the literature. The first is to identify cities with similar characteristics in terms of agricultural production. Thus, the units in the same cluster 
are provided with information about alternatives with which they can cooperate more effectively in future decision-making and implementation processes. The second contribution of the study is to show that some cities can produce more individually than tens of cities in combination. Thus, it is possible to have information about the regions that perform low production despite having sufficient opportunities.

In this sense, we consider that a strategic and sustainable mechanism needs to be established to ensure agricultural growth, including successful central strategic planning, well-disciplined local practices and performance assessments. Central strategic planning, which takes regional situations into account, can lead to the level-headed distribution of agricultural production across the country. In this way, in compliance with particular local characteristics or circumstances, plant and animal products can be supplied. On the other hand, well-disciplined practices can help to enhance distinctive local production. In terms of ensuring sustainable growth, increasing welfare, and reducing external dependency, all of these initiatives primarily serve the country. It is therefore possible to achieve sustainable agricultural production.

In this analysis, we needed to find quality data for all the parameters because it was empirical. However, it was difficult to find data available for all criteria and all towns because the database is limited. To eliminate such limitations, the database should be developed in terms of data diversity and regularity. The following agricultural variables should be established in this context: fishing production; greenhouse production; pasture fields; geographic, climatic, and irrigation conditions; and soil quality.

Finally, we emphasize the importance of creating a Turkey-specific index that will enable the comparative evaluation of local agricultural performance. This will allows for a simple, comparative and logical evaluation of regional or local contributions to the overall output. For policy-makers and practitioners, a further suggestion would be to constantly track local and regional agricultural output in order to recognize problem areas and develop effective strategies and solutions.

\section{References}

[1] Adalı, E. A. and Işık, A. T. (2017). CRITIC and MAUT methods for the contract manufacturer selection problem. European Journal of Multidisciplinary Studies, 2(5), 93-101. doi: 10.26417/ejms.v5i1.p93-101

[2] Arbolino, R., Carlucci, F., Cirà, A., Ioppolo, G. and Yigitcanlar, T. (2017). Efficiency of the EU regulation on greenhouse gas emissions in Italy: The hierarchical cluster analysis approach. Ecological Indicators, 81, 115-123. doi: 10.1016/j.ecolind.2017.05.053

[3] Bagočius, V., Kazimieras Zavadskas, E. and Turskis, Z. (2014). Selecting a location for a liquefied natural gas terminal in the Eastern Baltic Sea. Transport, 29(1), 69-74. doi: 10.3846/16484142.2014.897996

[4] Baležentis, A., Baležentis, T. and Misiunas, A. (2012). An integrated assessment of Lithuanian economic sectors based on financial ratios and fuzzy MCDM methods. Technol. Econ. Dev. Econ., 18(1), 34-53. doi: 10.3846/20294913.2012.656151

[5] Behzadian, M., Otaghsara, S. K., Yazdani, M. and Ignatius, J. (2012). A state-of the-art survey of TOPSIS applications. Expert Systems with applications, 39(17), 13051-13069. doi: 10.1016/j.eswa.2012.05.056

[6] Blashfield, R. K. (1976). Mixture model tests of cluster analysis: Accuracy of four agglomerative hierarchical methods. Psychological Bulletin, 83(3), 377-388. doi: 10.1037/0033-2909.83.3.377

[7] Chen, S. M. and Lee, L. W. (2010). Fuzzy multiple attributes group decision-making based on the interval type-2 TOPSIS method. Expert systems with applications, 37(4), 2790-2798. doi: 10.1016/j.eswa.2009.09.012

[8] Diakoulaki, D., Mavrotas, G. and Papayannakis, L. (1995). Determining objective weights in multiple criteria problems: The critic method. Computers \& Operations Research, 22(7), 763770. doi: 10.1016/0305-0548(94)00059-h 
[9] Everitt, B. S. and Merette, C. (1990). The clustering of mixed-mode data: a comparison of possible approaches. Journal of Applied Statistics, 17(3), 283-297. doi: 10.1080/02664769000000001

[10] Gradilla-Hernández, M. S., de Anda, J., Garcia-Gonzalez, A., Meza-Rodríguez, D., Montes, C. Y. and Perfecto-Avalos, Y. (2020). Multivariate water quality analysis of Lake Cajititlán, Mexico. Environmental monitoring and assessment, 192(1), 1-22. doi: 10.1007/s10661-019-7972-4

[11] Gupta, R. and Gill, N. S. (2012). A solution for preventing fraudulent financial reporting using descriptive data mining techniques. International Journal of Computer Applications, 58(1), 22-28. doi: $10.5120 / 9247-3411$

[12] Hair, J.F. and Black, W.C. (2000). Cluster Analysis. In Grimm, L. G. and Yarnold, P. R. (Eds) Reading and Understanding More Multivariate Statistics (pp. 147-205). American Psychological Association. doi: 10.5860/choice.38-5067

[13] Han, J. and Ge, Z. (2020). Effect of dimensionality reduction on stock selection with cluster analysis in different market situations. Expert Systems with Applications, 147, 113226. doi: 10.1016/j.eswa.2020.113226

[14] Hatry, H. P. (2006). Performance Measurement: Getting Results. Washington: The Urban Institute Press. 2nd Edition.

[15] Hervada-Sala, C. and Jarauta-Bragulat, E. (2004). A program to perform Ward's clustering method on several regionalized variables. Computers \& Geosciences, 30(8), 881-886. doi: 10.1016/j.cageo.2004.07.003

[16] Hong, X., Wang, J. and Qi, G. (2014). Comparison of spectral clustering, K-clustering and hierarchical clustering on e-nose datasets: Application to the recognition of material freshness, adulteration levels and pretreatment approaches for tomato juices. Chemometrics and Intelligent Laboratory Systems, 133, 17-24. doi: 10.1016/j.chemolab.2014.01.017

[17] Johnson, R.A. and Wichern, D.W. (2007). Applied Multivariate Statistical Analysis. New Jersey: Pearson Prentice Hall. 6th Edition.

[18] Khanykov, I. G. (2019). Technique for Acceleration of Classical Ward's Method for Clustering of Image Pixels. In: 2019 International Russian Automation Conference (RusAutoCon). doi: 10.1109/rusautocon.2019.8867747

[19] Kim, G., Park, C. S. and Yoon, K. P. (1997). Identifying investment opportunities for advanced manufacturing systems with comparative-integrated performance measurement. International Journal of Production Economics, 50(1), 23-33. doi: 10.1016/s0925-5273(97)00014-5

[20] Le Thi, H. A., Damel, P., Peltre, N. and Phuc, N. T. (2014). The Confrontation of Two Clustering Methods in Portfolio Management: Ward's Method Versus DCA Method. In Van Do, T., Le Thi, H. A. and Nguyen, N. T. (Eds.) Advanced Computational Methods for Knowledge Engineering (pp. 87-98). Cham, Switzerland: Springer. doi: 10.1007/978-3-319-06569-4_6

[21] Li, X., Wang, K., Liu, L., Xin, J., Yang, H. and Gao, C. (2011). Application of the entropy weight and TOPSIS method in safety evaluation of coal mines. Procedia Engineering, 26, 2085-2091. doi: 10.1016/j.proeng.2011.11.2410

[22] Lima Junior, F. R., Osiro, L. and Carpinetti, L. C. R. (2014). A comparison between Fuzzy AHP and Fuzzy TOPSIS methods to supplier selection. Applied soft computing, 21, 194-209. doi: 10.1016/j.asoc.2014.03.014

[23] Minatour, Y., Bonakdari, H., Zarghami, M. and Bakhshi, M. A. (2015). Water supply management using an extended group fuzzy decision-making method: a case study in north-eastern Iran. Applied Water Science, 5(3), 291-304. doi: 10.1007/s13201-014-0191-9

[24] Miszczyńska, K. (2013). Multivariate analysis of healthcare systems in selected European Union countries. Cluster analysis. Metody Ilościowe w Badaniach Ekonomicznych, 14(2), 99-107. cejsh.icm.edu.pl

[25] Mulliner, E., Malys, N. and Maliene, V. (2016). Comparative analysis of MCDM methods for the assessment of sustainable housing affordability. Omega, 59, 146-156. doi: 10.1016/j.omega.2015.05.013

[26] Murtagh, F. and Legendre, P. (2014). Ward's hierarchical agglomerative clustering method: which algorithms implement Ward's criterion?. Journal of classification, 31(3), 274-295. doi: 10.1007/s00357-014-9161-z

[27] Nakamura, Y., Mori, T., Sato, M. A. and Ishii, S. (2007). Reinforcement learning for a biped robot based on a CPG-actor-critic method. Neural networks, 20(6), 723-735. doi: 
10.1016/j.neunet.2007.01.002

[28] Nalbantoğlu, G. and Cakmak, B. (2007). Benchmarking of irrigation performance in Akınc1 Irrigation District. Journal of Agricultural Sciences. 13(3), 213-223. https://agris.fao.org/agrissearch/search.do?recordID $=$ TR2008000028

[29] O'Donnell, C. J. (2010). Measuring and decomposing agricultural productivity and profitability change. Australian Journal of Agricultural and Resource Economics, 54(4), 527-560. doi: $10.1111 / \mathrm{j} .1467-8489.2010 .00512 . \mathrm{x}$

[30] Opricovic, S. and Tzeng, G. H. (2004). Compromise solution by MCDM methods: A comparative analysis of VIKOR and TOPSIS. European journal of operational research, 156(2), 445-455. doi: 10.1016/s0377-2217(03)00020-1

[31] Pan, B., Liu, S., Xie, Z., Shao, Y., Li, X. and Ge, R. (2021). Evaluating operational features of three unconventional intersections under heavy traffic based on CRITIC method. Sustainability, 13(8), 4098. doi: 10.3390/su13084098

[32] Park, J. H., Park, I. Y., Kwun, Y. C. and Tan, X. (2011). Extension of the TOPSIS method for decision making problems under interval-valued intuitionistic fuzzy environment. Applied Mathematical Modelling, 35(5), 2544-2556. doi: 10.1016/j.apm.2010.11.025

[33] Pérez, E. A. and Nadal, J. R. (2005). Host community perceptions a cluster analysis. Annals of Tourism Research, 32(4), 925-941. doi: 10.1016/j.annals.2004.11.004

[34] Punj, G. and Stewart, D. W. (1983). Cluster analysis in marketing research: Review and suggestions for application. Journal of marketing research, 20(2), 134-148. doi: $10.1177 / 002224378302000204$

[35] Redwood, M. (2009). Introduction. In Redwood, M. (Eds.) Agriculture in Urban Planning: Generating Livelihoods and Food Security. (pp. 1-19). Dunstan House: Earthscan.

[36] Rosić, M., Pešić, D., Kukić, D., Antić, B. and Božović, M. (2017). Method for selection of optimal road safety composite index with examples from DEA and TOPSIS method. Accident Analysis \& Prevention, 98, 277-286. doi: 10.1016/j.aap.2016.10.007

[37] Sun, L. Y., Miao, C. L. and Yang, L. (2017). Ecological-economic efficiency evaluation of green technology innovation in strategic emerging industries based on entropy weighted TOPSIS method. Ecological indicators, 73, 554-558. doi: 10.1016/j.ecolind.2016.10.018

[38] Wang, J. J., Jing, Y. Y., Zhang, C. F. and Zhao, J. H. (2009). Review on multi-criteria decision analysis aid in sustainable energy decision-making. Renewable and Sustainable Energy Reviews, 13(9), 2263-2278. doi: 10.1016/j.rser.2009.06.021

[39] Ward Jr, J. H. (1963). Hierarchical grouping to optimize an objective function. Journal of the American Statistical Association, 58(301), 236-244. doi: 10.1080/01621459.1963.10500845

[40] Wu, H. W., Zhen, J. and Zhang, J. (2020). Urban rail transit operation safety evaluation based on an improved CRITIC method and cloud model. Journal of Rail Transport Planning \& Management, 16, 100206. doi: 10.1016/j.jrtpm.2020.100206

[41] Yang, W., Xu, K., Lian, J., Ma, C. and Bin, L. (2018). Integrated flood vulnerability assessment approach based on TOPSIS and Shannon entropy methods. Ecological Indicators, 89, 269-280. doi: 10.1016/j.ecolind.2018.02.015

[42] Yu, C., Baune, B. T., Fu, K. A., Wong, M. L. and Licinio, J. (2018). Genetic clustering of depressed patients and normal controls based on single-nucleotide variant proportion. Journal of affective disorders, 227, 450-454. doi: 10.1016/j.jad.2017.11.023

[43] Zhang, K., Zhan, J. and Yao, Y. (2019). TOPSIS method based on a fuzzy covering approximation space: An application to biological nano-materials selection. Information Sciences, 502, 297-329. doi: $10.1016 /$ j.ins.2019.06.043

[44] Žižović, M., Miljković, B. and Marinković, D. (2020). Objective methods for determining criteria weight coefficients: A modification of the CRITIC method. Decision Making: Applications in Management and Engineering, 3(2), 149-161. doi: 10.31181/dmame2003149z 